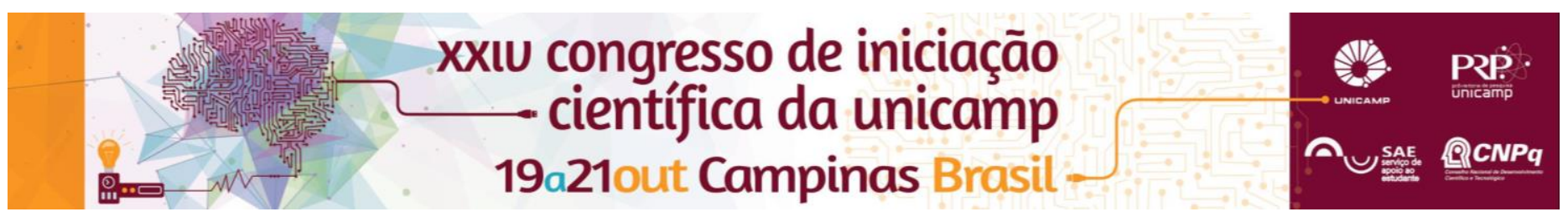

\title{
Remoção de íons prata e cobre em sistema adsortivo de leito fixo de argila bentonítica verde-lodo.
}

\author{
Hewellyn J. de Almeida*, Emanuelle D. Freitas, Melissa G. A. Vieira.
}

\section{Resumo}

O desenvolvimento de processos industriais que envolvem metais tóxicos aumentou a produção de efluentes contaminados com esses compostos e a preocupação em investigar métodos cada vez mais eficientes de tratamento. Este projeto visou avaliar a remoção dos íons metálicos de prata e cobre, em solução aquosa binária, utilizando argila bentonítica Verde-lodo como adsorvente alternativo. Os ensaios foram realizados em sistema dinâmico de leito fixo, para a obtenção das curvas de ruptura e de seus respectivos parâmetros de eficiência e de transferência de massa. A vazão e a concentração inicial dos íons foram variadas a fim de determinar as condições ótimas de operação e analisar a influência das frações molares e concentrações totais de íons no processo adsortivo. Verificou-se que a vazão de $3 \mathrm{~mL} / \mathrm{min}$ apresentou melhores valores de Zona de Transferência de Massa (ZTM) e \%Remoção e que o cobre foi mais seletivo. O tempo de vida útil da coluna foi avaliada por meio de ciclos de adsorção/dessorção, visando a recuperação dos metais de interesse por eluição com ácido nítrico. Para analisar o comportamento da argila após a dessorção, o adsorvente foi caracterizado por DRX, termogravimetria, FT-IR e MEV.

\section{Palavras-chave:}

Adsorção binária, prata, cobre.

\section{Introdução}

Estudos de adsorção multicomponentes em sistemas dinâmicos são os que mais se aproximam do tratamento de efluentes em escala industrial. A otimização desse processo é, portanto, essencial para garantir a preservação do meio ambiente e a sustentabilidade financeira da empresa. Esse estudo visou investigar o processo de adsorção binária de íons $\mathrm{Ag}(\mathrm{I})$ e $\mathrm{Cu}(\mathrm{II})$ em argila Verde-lodo, através de coluna de leito fixo. Foi analisada a influência da vazão e da concentração e a regenerabilidade da argila após a dessorção.

\section{Resultados e Discussão}

A partir da especiação metálica nos programas Hydra® e

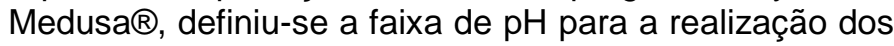
experimentos entre 0 e 5 , na qual não ocorre precipitação química dos metais de interesse.

O estudo fluidodinâmico foi realizado com as vazões de 1,2 , 3 e $5 \mathrm{~mL} / \mathrm{min}$ e solução equimolar de $1 \mathrm{mmol} / \mathrm{L}$ de cada metal. $\mathrm{O}$ ensaio a $3 \mathrm{~mL} / \mathrm{min}$ resultou nos melhores parâmetros de eficiência, com menor ZTM $(8,15 \mathrm{~cm}$ para o cobre e $6,14 \mathrm{~cm}$ para a prata) e maior remoção (47\% para o cobre e $45 \%$ para a prata). A Figura 1 apresenta as curvas de ruptura para a vazão ótima de operação.

Figura 1. Curvas de ruptura para a vazão de $3 \mathrm{~mL} / \mathrm{min}$.

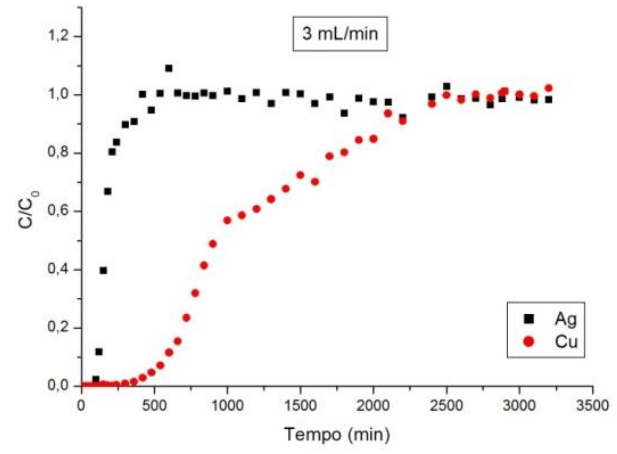

Na vazão ótima, foram realizados ensaios com diversas frações molares dos metais. Notou-se a melhor afinidade do cobre em detrimento da adsorção de prata. Os melhores parâmetros de eficiência foram obtidos para a máxima concentração total inicial $(2 \mathrm{mmol} / \mathrm{L})$, sendo a maior \%Rem de $47 \%$ para a prata e $48 \%$ para o cobre.

Dois ciclos de adsorção/dessorção foram realizados na condição ótima de operação, utilizando $\mathrm{HNO}_{3}$ a $0,1 \mathrm{M}$ como eluente. $\mathrm{Na}$ segunda adsorção, ocorreu o fenômeno de overshoot para a prata, devido a sua substituição pelos íons de cobre nos poros já ocupados. O fenômeno impossibilitou o cálculo dos parâmetros para esse metal e a continuidade de novos ciclos. A Tabela 1 dispõe alguns dos parâmetros obtidos para cada ensaio.

Tabela 1. Parâmetros de eficiência dos ciclos.

\begin{tabular}{|l|c|l|l|l|l|}
\hline & Metal & $\begin{array}{l}\mathrm{q}_{\mathrm{t}} \\
(\mathrm{mmol} / \mathrm{g})\end{array}$ & $\%$ & $\begin{array}{l}\text { qel } \\
(\mathrm{mmol} / \mathrm{g})\end{array}$ & $\% \mathrm{El}$ \\
\hline Ciclo 1 & $\mathrm{Ag}$ & 0,022 & 46,65 & 0,020 & 89,18 \\
\cline { 2 - 6 } & $\mathrm{Cu}$ & 0,114 & 48,20 & 0,088 & 76,10 \\
\hline Ciclo 2 & $\mathrm{Ag}$ & - & - & 0,024 & - \\
\cline { 2 - 6 } & $\mathrm{Cu}$ & 0,129 & 41,56 & 0,087 & 67,65 \\
\hline
\end{tabular}

A partir das técnicas analíticas de DRX, TG, MEV e FT$\mathrm{IR}$, observou-se que o eluente afetou a morfologia das partículas, porém não alterou sua estrutura cristalina, grupos funcionais e estabilidade térmica.

\section{Conclusões}

Nos experimentos, verificou-se a maior seletividade do cobre, com máxima remoção simultânea de $47 \%$ de prata e $48 \%$ de cobre. A vazão ótima definida foi de 3 $\mathrm{mL} / \mathrm{min}$ e os ciclos de adsorção se mostraram eficientes na recuperação dos metais. A partir da caracterização da argila foi possível perceber mudanças morfológicas na partícula, mas sem alteração estrutural.

\section{Agradecimentos}

Ao PIBIC/CNPq, à FAPESP e ao SAE/UNICAMP, pelo suporte financeiro. 